\title{
Mothers' Accounts of Attending to Educational and Everyday Needs of Their Children at Home during COVID-19: The Case of the UAE
}

\author{
Fatma F. S. Said ${ }^{1, *(\mathbb{D},}$, Nadine Jaafarawi ${ }^{1}\left(\mathbb{D}\right.$ and Anna Dillon ${ }^{2}(\mathbb{C}$ \\ 1 Language Studies Department, College of Humanities and Social Sciences, Zayed University, P.O. Box 144534, \\ Abu Dhabi, United Arab Emirates; Nadine.jaafarawi@zu.ac.ae \\ 2 College of Education, Zayed University, P.O. Box 144534, Abu Dhabi, United Arab Emirates; \\ Anna.dillon@zu.ac.ae \\ * Correspondence: fatma.said@zu.ac.ae
}

check for updates

Citation: Said, Fatma F. S., Nadine Jaafarawi, and Anna Dillon. 2021.

Mothers' Accounts of Attending to Educational and Everyday Needs of Their Children at Home during COVID-19: The Case of the UAE. Social Sciences 10: 141. https:// doi.org/10.3390/socsci10040141

Academic Editor: María

José González

Received: 27 February 2021

Accepted: 9 April 2021

Published: 15 April 2021

Publisher's Note: MDPI stays neutral with regard to jurisdictional claims in published maps and institutional affiliations.

Copyright: (c) 2021 by the authors. Licensee MDPI, Basel, Switzerland. This article is an open access article distributed under the terms and conditions of the Creative Commons Attribution (CC BY) license (https:// creativecommons.org/licenses/by/ $4.0 /)$.

\begin{abstract}
From March 2020 until July 2020, the UAE implemented mandatory distance learning due to COVID-19, which meant that children had to continue their learning remotely at home. Though schools concerted exemplary efforts to ensure that children received all that was necessary through advanced technology platforms and interfaces, the duty of ensuring that children continued to engage in successful learning fell solely on parents. This paper is based on a self-report study conducted during this first period of distance learning where parents were invited to anonymously complete a survey and then be interviewed. The paper relies on interviews as its main data source. Interview transcripts once transcribed were thematically analysed. One recurring theme in the data was gender differences in domestic and other duties as well as attending to the educational needs of children. Mothers, irrespective of cultural or educational background, disproportionately seemed to be the caretakers of the home and of children's educational needs. Mothers spoke of their mental health concerns, pressures of time management, and negative effects on their own work. This paper makes an original contribution by exploring parental experiences of emergency remote learning and what these reflect about parental ethnotheories in the UAE.
\end{abstract}

Keywords: COVID-19; emergency remote learning; UAE; motherhood; parental ethnotheories

\section{Introduction}

The ongoing global COVID-19 pandemic is forcing the education sector to face some of the biggest changes in education since public schooling emerged over two centuries ago (UNESCO 2020a). These changes can be seen not only in public schooling but also in private schooling. Indeed, in addition to observing both public and private schooling separately, it is possible that "A certain privatization occurs when learning moves from schools into the home" (UNESCO 2020a, p. 7). This pandemic has seen a "shift away from learning and teaching in traditional settings with physical interactions" (UNESCO 2020a, p. 7), towards a distance, online or blended approach, in many cases combining a learning from home model supported by teachers in public and private schools. However, the models of education vary all over the world "according to the availability of resources and capacity" (UNESCO 2020c, p. 1). In this context, "the family more than ever constitutes a learning space, in which parents and caregivers act as primary guides to support their children's learning at home" (UNESCO 2020c, p. 1).

At the time of writing, "education is expected to be shifting between in-person learning and remote learning, or a combination of them, as virus resurgence is anticipated" (UNESCO 2020b, p. 7), bringing with it a high level of uncertainty about "how long and to what extent the pandemic will continue to impact education systems across the globe" (UNESCO 2020b, p. 8). With many parents supporting children's learning from home, 
many communities have come to a deeper "appreciation of teachers' work and their professionalism" (UNESCO 2020a, p. 7). Schools play multiple roles in children's lives, not only in relation to academic learning but also in ensuring the wellbeing of children in all developmental domains. In a time when the whole area of knowledge and learning was already being rethought and reimagined, for example, with initiatives such as UNESCO's Futures of Education: Learning to become (2019) initiative, the pandemic has brought a more pressing urgency to this endeavour. Education is being reconceptualized as we move through the global, national, and local responses of various education boards. It is more important than ever to consider the role of parents in the education of their children, especially as many educational settings are relying on the support of parents in helping their students achieve learning outcomes within an emergency remote learning (ERL) model.

In the UAE, schools have been on lockdown since March 2020, with some currently (in March 2021) operating in hybrid modes (offering off-line (with COVID precautions) or on-line learning) or exclusively online. Demographically, the UAE has the highest concentration of private schools in the world (Gallagher 2019) due mainly to its very distinctive demographic landscape in terms of the ratio of citizens to non-citizens. In the capital emirate of Abu Dhabi, Emirati national citizens made up almost $20 \%$ of the population in 2016, while in the commercial centre emirate of Dubai, less than $10 \%$ of the population was Emirati in 2017 (Gallagher 2019). The UAE is an example of a particular context where the "host culture" (Emiratis) is a minority. Third Culture Kids (TCKs) are children who spend time in a host country during their developmental years away from their country of origin, typically their passport country. Given the significant numbers of expatriates in the UAE, TCKs can be found in every classroom in every private school. In "dual career couples", it is common for both parents to be employed in the UAE, particularly given the development in the labour market and the transnational employability of workers across many sectors.

The COVID-19 pandemic has spurred a stream of research (McLaren et al. 2020; O'Reilly 2020; Russell et al. 2020) examining the impact that this pandemic has had on women. In their study, McLaren et al. (2020) studied the impact that the pandemic has had on women from countries such as Australia, Vietnam, Malaysia, and Sri Lanka. The authors examined the escalations of women's burdens in the times of COVID-19 disaster across different vignettes, namely, unpaid care work, community activities, and frontline work. The study found that the COVID-19 pandemic intensified women's existing triple roles of carrying out productive, reproductive, and community work. However, the authors note that COVID-19 has only intensified the women's existing burdens which, according to the authors, have been imposed collectively in their society and as a part of cultural traditions in almost all countries. For example, terming countries, such as Sri Lanka, Vietnam, and Malaysia, as highly patriarchal, McLaren et al. (2020) stated that women in these countries are often, due to cultural pressures, asked to confine to indentured servitude, where carrying out gendered duties are viewed as a luxury for women rather a burden.

In their recent paper, Lee et al. (2020) revealed through their analysis of social media posts in Korea that COVID-19 substantially changed the meaning of home in Korea from a place to sleep to a basecamp involving numerous major activities related to work, schooling, parenting, housework, shopping, leisure, and religion. They stressed that although the pandemic provided an opportunity to build emotional ties for some families, many families who were stuck at home experienced relational difficulties. This fact has caused gender inequality along with discrimination against certain groups to surface. Korean families have found it challenging to spend intensive time with their family, to share gendered family responsibilities, and to support other families. The authors suggested that employed mothers were likely to be the most overloaded given the gendered division of care and housework in Korea. Caring for children was a particularly challenging task for mothers, and in most families, mothers had to assume the primary responsibility for their children's education along with an increased amount of housework (Samuelson et al. 2017; Self and 
Grabowski 2011). Furthermore, for employed mothers, working from home meant frequent shifts or simultaneous practice between work and family responsibilities.

In addition to Korea, in Italy, due to the increase in remote work, the redistribution of domestic childcare responsibilities in terms of gender relations during the COVID-19 lockdown period was unequal (Manzo and Minello 2020). The lockdown had an effect not only on the gendered division of care but also on the resources that can be mobilized to activate social support in the organization of care. In their research, Manzo and Minello (2020) collected 20 real-time online interviews in which all participants clearly expressed a complete rescheduling of their daily activities. Almost all mothers were taking care of their children during the lockdown, sacrificing their work time, and putting into place diverse strategies to cope with the new situation, from radical reorganizations of their home spaces to ongoing negotiations with their children over the supply of snacks and screen time and even breastfeeding to carve out time to work. The remote-working mothers who participated in their study reported that they primarily worked when their children were sleeping (Manzo and Minello 2020). The couples who attempted to support each other between calls and deadlines, and tended to divide childcare equally, were scarce. Reaching a compromise between fathers and mothers in sharing children's care did not necessarily mean finding a balance. The researchers reported that the participants in the study often expressed discouragement and frustration. Their virtually collected data illustrated the centrality of mothers' emotional resources to deal with the pandemic as care leaders (see also Borah Hazarika and Das 2020).

Even though the COVID-19 pandemic may have aggravated the problems of women and mothers and added to their usual responsibilities, the need to take care of children's education is also reinforced because of the gender bias that exists in various cultures around the world where women or mothers are asked to play an important role in educating their children. It is worth noting that even though culture plays a vital role in making mothers more responsible for their children's education than fathers, there are also various other factors which have been considered to have reinforced this role of mothers as primary educators of their children. For example, over the years, a stream of research examining the benefits of the role of mothers as educators has emerged. Some researchers express strong opinions about the role of mothers in education; for example, Erawati (2020) claims in her study, "[a] mother has a very important role in educating their children and encouraging a child ... [i]n terms of education a more powerful mother has ambitions in determining success for their children" (p. 51). Explaining the importance of the role of mothers in the growth of children, Ceka and Murati (2016) reiterate the views of Erawati (2020) when they state that "[e]ach child which grows up and is educated in the presence of mother, for sure is expected to reach an appropriate physical, psychological as well as social development" (p. 62). The authors state that it is the biological and psychological relationship that the mother shares with her children that make it easier for the mother than the father to play a crucial role in these developmental domains. Finally, it is important to underline that it is not just the influence of culture on women that defines roles for women as educators of children, but it is also the influence of culture on men that reinforces the role of women as educators.

Beliefs about roles mothers play in their children's upbringing or in education are constructed at social and personal ideological levels. They are referred to as "parental ethnotheories" and are defined as "the nexus through which elements of the larger culture are filtered, and as an important source of parenting practices and the organization of daily life for children and families" (Harkness and Super 2006, p. 62). These cultural beliefs "influence practices" that ultimately "define relationships within the family" (Harkness et al. 2015, p. 1). The paper makes the argument that the burden on mothers during COVID-19 ERL cannot be understood independent of parental ethnotheories or ideologies of how society or mothers themselves view their roles, since these influence greatly how parents behave and the choices they make. 
It is, therefore, of interest to understand how, if, and to what extent such trends are also present in the participants from the UAE who took part in this study. The next section introduces the methodology used for this study.

\section{Methodology}

This data-driven project did not utilize one specific framework through which to explore the above-mentioned phenomenon. It was exploratory in nature (Stebbins 2001) and endeavoured to understand parents' experiences of ERL and how they balanced family and work time. The aim was to focus on the issues that arose in the data and then further investigate how these inform the researchers about the ERL experience. The research was designed to investigate a current real-life problem. The project asked the following broad research questions: "What are parental experiences of emergency remote learning (ERL)?" and "What cultural beliefs influence parental roles in this context?".

Data were collected in the form of an online survey that was adapted from a validated standard Basic Needs Satisfaction Scale survey (Johnston and Finney 2010). In addition to demographic information, the survey asked about autonomy, competence, and relatedness in parents. Participants had the option to leave their email addresses and names at the end of the survey if they wished to be part of the interview phase. This paper focuses on the interview responses only allowing a deeper understanding of parental views and their experiences.

Interviews were conducted to further understand parents' experiences during ERL (Doody and Noonan 2013). The interviews were conducted once the questionnaire data were collected, and this method allowed researchers to further explore aspects important to parents during this time (Smith and Firth 2011). Overwhelmingly, mothers completed the questionnaires and volunteered to be interviewed, with the exception of one father. Interviews were translated, transcribed, and checked by an independent research assistant. The transcripts were then thematically analysed (Braun and Clarke 2013) in six steps. First, familiarization of the data was achieved through careful close study of the transcripts. Then, codes were initially generated through organizing data by topic (e.g., difficulty of teaching at home, house chores, spending time with family, and hardships). This was followed by the generation of themes in which the researchers and one research assistant re-organised the already recognized themes from step 2 and reduced and refined the number of themes (positive aspect of distance learning and living situation; family configuration, challenging aspects of distance learning, issues related to language learning, parental involvement, family bonding, and disproportionate burden of duties on mothers). A final review of themes took place with the second research assistant to ensure inter-rater checks, with all researchers agreeing on the identified themes. The last step was producing a report or final set of themes (see Appendix B for an example of the themes and their data sources).

The researchers conducted the study ethically as set out by the UAE national research ethics committee and Zayed University ethics committee; once ethical clearance was given, researchers then publicized the project. Participants were invited to take part in the project through education-based mailing lists, parent-based WhatsApp groups, Facebook pages of school clubs, parent groups, early childhood learning centres, and through emails sent to the academic community in the UAE. All participants were required to sign a consent form and were informed about how their data would be stored, managed, and used. All participants were given pseudonyms for purposes of protecting their identities while reporting the findings.

\section{Results}

In all, 183 responses were selected as completed and usable from the survey (total was 203). Of those, 101 participants (55\%) declared themselves as Emirati nationals with the remaining $45 \%$ of other Arab origins, British, Australian, Greek, Turk, and American. In total, 52 parents volunteered to be interviewed, and these interviews were conducted and recorded via Zoom (see Appendix A for set interview questions), which lasted between 
15 and 20 min each. Parents were asked a number of set questions as well as those pertaining to the answers they provided in the survey or in the interview itself.

The findings presented here are on the interview transcripts. The paper focuses on the theme of the disproportionate burden of duties on mothers at home and in education ( $n=262$ quotations attributed to this theme), an aspect of focus that arose as a result of the exploratory data-driven design of this project. It warrants attention, because research in this area in the UAE is non-existent, and the findings here will contribute towards a global understanding of the human experience during COVID-19. The data directed the focus towards mothers' roles in attending to children's educational and other needs at home.

In addition to discussing the difficulties of managing distance learning, such as the need to buy extra computers or tablets and finding different rooms in the house to ensure each child had a quiet place to learn, mothers pointed out the extra burden they shouldered alone in ensuring a smooth experience for their children during ERL. Alia (France) says that "I make sure the night before that all the books they need or any printing for schools is done. So after dinner, I shower them, put them to bed and then I prepare and print. It's exhausting, but I need to do it" (Alia: INT: 007). She continues, "I don't really like to ask Malik because he would have just come home and he'd had a long day and it's okay I will work it out with the kids, at the weekend he helps". Similarly, Lama (UAE) says that "the most difficult thing I found was having to sit down and go through everything, I am the mother and so I must do that, it is my duty to make sure they learn. So, I printed their timetables and put them on the wall with all the passwords, it was hard, but my work helped me a lot" (Lama: INT:014). Alex (Greece) says that "I managed with great difficulty and at the expense of my own, not existent any more free time but really squeezing and getting as much as possible during the school hours focusing on the kids and working until late in the evening on my own things or late night actually. So, I don't feel that I managed this in a spectacular way" (Alex:INT:046). She adds that her husband helps with Arabic and mathematics at the weekend, but she feels "it is my responsibility to get on with them during the day, otherwise what are mothers for, if not to suffer a bit for the babies [laughs]". Ramona (Pakistan) says, "I sit with them whilst they are in class, each of them wears headphones and mutes their microphones so they do not disturb each other, we are now 5 in our sitting-dining area and I also do my work. I want to see how they are learning, and I want to help. Zulfikhar sits in the other room working, I want to be here to make sure they study" (Ramona: INT:038).

Andrea (U.S.A.) describes the shift in her life during ERL and how this increases the feelings of having to intensely take care of everything. Andrea finds that the demand to be a mother has increased dramatically. "I now no longer have space for myself or to even do the things I did before, like plan a well-organised Christmas with mum and dad coming to us ... or even just cleaning or sorting the home in a clean and organised way. Now, I have to take care of the girls and I can't take Lisa to the playgroup anymore. So, my hands are really full, and I feel like I need help, they are all here. Phil, the girls and it feels like there is no space because I can't go to the park or mall, though I enjoy spending time with them, it's too much". (Andrea: INT:005). In the same vain, Faiza explains the rationale behind her thinking during the ERL time, "I needed to make sure that Adam had a quiet place to study, that Ahmad got a new tablet and that I also had a space to work, we don't have enough space so I end up in the kitchen, but then I need to cook, do my own work, make sure I know what homework they have, sometimes they forget, but it's too hard for me, some days I don't know where I am" (Faiza: INT:004). The externalizing of the mother's internal pressure is clear through the long list and description of the duties she undertakes and how she feels about these. There is a sense of extreme pressure when Faiza (Lebanon) says that "some days" she does not know where she is. The mothers above seem to exhibit particular parental ethnotheories about their roles as mothers in taking care of their children's educational and other needs. Their cultural beliefs are that they should undertake such tasks, and they centre their actions around motherhood as opposed to parenthood, hence gendering this role and placing the burden on themselves and not their husbands. It seems from the account above and those to follow below that partners are als seen as individuals to prioritise and take of. The activities of ensuring correct school 
material are picked, the printing of worksheets and timetables, the tracing of students' work during the school days, as well as partners' wellbeing are all taken on by mothers.

The overall difficulties mothers experienced during the ERL times are unique to each mother. Nella (Italy), for example, says that "the idea that I have to do everything makes the whole thing difficult, I miss my parents who cancelled coming out here to see me and the kids. I am alone and there is no one to help me, so it's lonely and difficult" (Nella: INT:006). Rosa, from the UK, cites the effect such arrangements have on her health, "the fact is that I cannot do everything, I mean I say that, but I do end up doing it despite my ill health. My other half is out of the house and when he returns it's a lot for him, so I do it. I cook, clean, wash, do my own work, make sure the kids are doing their work, connection problems were a lot at the beginning but got better now, I am not sleeping very well too" (Rosa: INT: 018). Nella, Rosa, and Shaikha (UAE) report that their sleep has been affected, "I started to notice my sleep was affected maybe 3 weeks into distance learning, I was sleeping at two am and waking at five to get things ready for the kids, if I had to also work, I think I would have to give up work" (Shaikha: INT:023). Shaikha feels that the burden is great, even though she is not in employment. Rima (UK) says that "the pressure of being a mother and taking care of their schooling and their health and worrying about the screen time was tough for me in many ways, mentally it affected me and yes, physically" (Rima: INT:042).

The pressures of distance learning seem to affect mothers in employment and equally those who stay at home. Mothers reported feeling tired all the time without finding opportunities for actual effective rest. Anila (India) highlights this well, "usually you get to rest and relax and then it starts all over again, but now it's like every bit of your energy is completed deple ... deleted or like taken away. I look inside my and I have nothing and that's not good for them" (Anila: INT: 007). In this interview, Anila talks about energy as a resource she no longer has because her motherly duties have been increased by the lockdown and COVID-19 situation. Again, she seems to attribute all duties to herself and taking all responsibilities for care of her family and education of her children. Hayat (Canada) says that for her, "having to manage my home life with my 2 children, having to take some times out where I can sit on my laptop and my paperwork, my marking, my assessment with having my children around me is hard ... I need to be doing home learning with my child, my 4 year old child, obviously she needs a little bit of time dedicated to her and the others and then in the end I am being both teacher and mother that challenges me" (Hayat: INT:050). The idea of being a mother and teacher at the same time is the role she has taken on and she describes in vivid long responses how that has affected her own work.

Physical living arrangements appear to have affected mothers' abilities to effectively parent because "you can't go out during the lockdown and even if we could, it was just too hot to go to park, we would usually go the indoor playgrounds for hours as we have no garden or balcony" says Camile (Switzerland). She elaborates further, "having only 3 bedrooms it feels like going around in circles all day, room, sitting room, kitchen, toilet, room, and then they fight and push each other and cry and it's just so noisy and I try to think ... " (Camile: INT:011). Space was a problem and mothers said this impacted their abilities to work and to parent as they would have preferred. Similarly, Layan (Jordan) says that she converted her balcony into "a small space where we could all sit, at least to bring some air into the home, I also bought green plants and put those all around the flat, I was making the space nicer and also the plants bring in oxygen for us, but space made things harder for me, for their father and cooking and cleaning and sleeping in the same small area is tough, I think I was sometimes shouting more?" (Layan: INT:016). Layan perhaps feels she lost some control as a mother because of her increased shouting, and it seems she attributes that change in her parenting to the consequences of the small space she and her family live in. The small spaces intensified living during the ERL and may have placed more pressure on parents. On the other hand, Hanna (UAE) says that "at least we have the space otherwise, where would they all play? With my nieces as well? It would be too much"; she continues, "right now I can sit in the room at certain times and do my work, then go out in the garden with them, we also have an outer house where sometimes guests sit and the kids can run around there" (Hanna: INT:029). The extra space seems to suggest that parents 
had an opportunity not to always be in the same space as their children, perhaps reducing some of the pressures reported by Camile and Layan above.

The type of help received by parents was also an aspect the mothers discussed in the interviews. Of those interviewed, only six mothers had help either through nannies or maids. Steph (Australian) says that "without our maid, we were in real trouble, I mean having three kids, plus I work, Roy works, and we are all at home, it can become quite intense. Our maid cleans and does the washing, at least I only have to do the cooking, which is great" (Steph: INT: 001). Domestic help, therefore, lessened the burden on mothers, but even in this description, Steph is taking care to ensure that everything will run well and be helpful to her family. Fatima (Egyptian) on the other hand spoke of the struggles she encountered because her maid and nanny both travelled back to their respective countries and due to the lockdown could not return to the UAE. This created many challenges for her, "I had to ask my boss to take part-time or less work because there is no way that with three children and a baby on the way that I would be able to clean, cook, wash and make sure they are studying. Even though the school takes care of things, we still need to work and make sure they work... my mother was supposed to come from Egypt for the birth in two months from now, but she is on hold. I can't do this without help, Hamdy is a doctor and he is doing his bit to combat Covid" (Fatima: INT: 010). Fatima says that she asked for part time work rather than continuing full time because of the extra burdens of work at home. For some families, the loss of extra help had employment, and by default, financial, ramifications. Fatima's account depicts the challenges she underwent.

In contrast to the above, there were mothers who found the ERL at home a welcome change. Hala (UAE) says that "I get to see them more now and this helps in building my relationship with them, I discovered my daughter has a really good way of doing her math, I did not know before, it made me feel guilty" (Hala: INT:025). Some mothers were able to reassess their parenting with two mothers using the word "guilt" to express newfound knowledge about their children. Basha (Poland) says for her "it was all about trying to shut out all the troubles or hard things out and look at my children and appreciate them, with my job and running around, but all this running around was for them, but now I love being with them, it made me feel guilty to have been rushing too much before and not take time" (Basha: INT: 043). Basha seems to appreciate the extra time she has to re-focus on her children, something she says she has not been able to do due to work and a busy life. Some mothers felt that they had somehow overlooked such characteristics because of the busy life of going to school. Sara (Syria) says that "I actually enjoy having breakfast with them, my husband is also helping me more, he cooks sometimes when he can and really for me it's a dream to have all my hearts in one place at the same time" (Sara: INT: 019). For Sara, in addition to having her family at home with her much more, her husband is also helping, which seems to make her happy. Without a doubt, many families experienced such support and such fulfilment at having their children and families together more, albeit enforced, and many fathers not only helped but also took on integral support roles for their partners.

\section{Discussion}

The results presented parents' views of their experiences during COVID-19 ERL. Although the main topic of this paper reported mothers' difficulties during this time, all mothers expressed their happiness to parent and take care of their children and to be with their children. However, the new circumstances in which parenting is now taking place affected mothers more than fathers, in women's experiences as mothers, employees, and caretakers. It is too early to tell how far reaching these effects are on mothers' abilities to parent effectively or on their general outlook on parenting, but the findings here warrant extra attention and care to be paid to mothers, those at home, and especially those in work.

The data presented above complement much of the current research undertaken on COVID-19 ERL. First, Russell et al. (2020) indicate that the COVID-19 pandemic has led to an unprecedented impact on individuals' mental health. The findings here are in line with what they found in that, since families are confined to the same space due to the COVID-19 pandemic for an undefined period of time, it has had an impact on the mental health of 
parents, which include fathers, but more mothers, which in turn has serious consequences for child-parent relationships.

In other current research, similar experiences have been reported. For example, Almeida et al. (2020, p. 744) found that "[a] heavy load of parental stress came as a consequence, particularly for mothers, who typically carry the bulk of childcare and eldercare in most parts of the world". Andrew et al. (2020), in their study on UK families, found that as a result of the lockdown and distance learning that "mothers are also far more likely to be interrupted during paid working hours than father". They conclude that "where focused work time is important for performance, gender differences in interruption and multitasking risk further increasing the gender wage gap among parents". The current overburden of duties seems to have overarching effects on the future of women's careers and chances of advancing the workplace; such facts affect single mothers or those without access to extra funds.

With regard to the burden that the pandemic has had on mothers, Guy and Arthur (2020) explored academic mothers working from home and the effect of the lockdown on their mental health. They asserted that being a working mother is tough but being a mother during COVID-19 is more difficult than one could have ever imagined. Working mothers, particularly in academia, are struggling to keep up with their male counterparts more than ever before. Through an interview with two mothers working in an academic setting, it was clear that society needs to do a better collective job of being more mindful and realistic in its expectations of working mothers. The authors hoped that by showcasing the vulnerability of those mothers, they could lead the change in the expectations that society puts on mothers in academia.

Mothers or females more than any other group are disproportionately affected for a number of reasons, particularly because of carrying all or most of the burdens related to parenting and educating their children. Sher (Sher 2020) conducted research on the effect COVID-19 has on wellbeing and found that the stresses related to additional responsibilities, notwithstanding the already existent anxieties of the pandemic itself, affected sleep.

O'Reilly (2020) found that since COVID-19 has cancelled most outdoor activities for children, mothers have little or no respite from their schedules. The intense forced time together worked well for some families and mothers, who saw this intense time as positive in their relationship building; this was especially true for mothers who had help, such as Sara, either through a partner or domestic help. However, this was much less often the case among working mothers and especially those who did not have help.

Each mother describes the difficulties faced as a result of ERL, and the paper argues here that these perceptions, whilst based on actual facts, were the result of parental ethnotheories. Fogle (2013, p. 85) aptly underlines that "cultural ideas about children and childhood have implications for childrearing" in that decisions parents, or in this case, mothers, make are based on how they envision their role of mother. Of those with partners or husbands, very few mentioned their husbands or partners in these accounts of their feelings and experiences during ERL. Instead, they focused on themselves and their role as the mother and caretaker of everyone and everything within their homes. These beliefs may have dictated the allocation of work within the home and how much contribution mothers expected fathers to make. This is not to refute the studies cited above on gender inequality around the world, but the literature on ethnotheories underlines that these are deeply ingrained ways of thinking that did not materialise in a generation or two. Ideas about motherhood that have been cultivated for centuries by both men and women themselves with contributions from culture and religion further define the different kinds of existent ethnotheories today. Fogle (2013, p. 99) explains that these ideologies "involve discourses engrained in parents' own socialization and histories, discourses appropriated from public sources such as expert or medical advice, and discourses that develop within the family among family members as ways to explain day-to-day processes and emerging identities". It seems that these strong ethnotheories played a major role in how mothers, in particular, defined their roles during the COVID-19 lockdown. The authors here are 
acutely aware that ethnotheories are also dynamic in that each family or parent defines their own cultural beliefs. However, in this paper, it appears that regardless of culture or religion, similar ethnotheories seem to be present in the data, that mothers are ultimately responsible for their children's learning, that mothers should take care of the home, and that mothers should prioritise others before themselves. The mention of cultural or other pressures or feelings of contempt towards these "motherly" duties is missing from these accounts. Again, it is unclear whether mothers wanted their partners to help, as many in this project simply said their partners had to work or remained neutral about their own expectations of what they would have liked their partners to do. It would appear that fathers, partners, and others simply played the role of supporter in helping mothers take on their roles as caretaker of educational and other needs during COVID-19.

Mothers and fathers are socialized early into their roles, which affects how they will parent later themselves and how they view their own and their partners' roles in parenting. Pancsofar et al. (2019) examined the perspectives of fathers regarding their involvement in their children's education and schooling. The authors found that fathers' employment was seen as a reason not to be directly involved in their children's education and schooling. However, their employment was also found to serve as a barrier to more direct involvement in the schooling of their children. In addition, various other factors hampered fathers' involvement in children's education but encouraged a greater role or involvement of mothers in school settings. In other words, the study found that even though fathers play important roles in their children's education, they often feel left out of the educational system. This alienation was a direct result of the roles that mothers are predominantly asked to play or assign to themselves in child development, including spending more time with children and playing dominant roles of caregiving in their families. The gendering of childcare has been further extended into the gendering of home schooling and caretaking duties during the pandemic, as this study showed. The COVID-19 pandemic has clearly highlighted the indelible impact parental ethnotheories, early socialization, and society's demarcation of male and female caretaking roles on how roles were undertaken during ERL.

Finally, the data showed the role mothers have played in attending to the educational and other needs of their children and families during ERL in the UAE. These roles were not new but merely intensified because of COVID-19, hence pushing mothers to their limits. Even without the pressures of a pandemic, all over the world, as illustrated by the survey of literature above, parental ethnotheories and other factors mean that mothers already undertake most caretaking duties for their families. Future research could investigate children's experiences of ERL and their transitioning back to face-to-face education as well as further explore some of the issues addressed above at a larger scale.

\section{Recommendations}

In conclusion, this paper recommends that parents and mothers in particular be supported to safeguard their mental health caused by the effects of social isolation, intense parenting, and caretaking duties. Mothers make a choice to become parents and to take care of their children. They should be supported at work by their employers through schemes that assist them to simultaneously conduct their family duties without penalties or loss of pay as much as is possible. The presence of women in the workplace has benefitted the economy of countries, the quality of lifestyle, and the work experience of employees, and changed the way in which business is conducted (see, for example, Matsa and Miller 2014; O'Neill 2016; Taneja et al. 2012). Such advancements in the human experience of work as a result of women entering and influencing the workforce must be maintained and extended. By establishing these above recommendations, it is hoped, to some extent, that women's choices in life and in duties they assign to themselves will be safeguarded and preserved. In addition, it is hoped that they also receive effective assistance during such pressure-filled situations now and in the future. 
In the UAE, for example, the Ministry of Human Resources and Emiritization (MoHRE 2021) has given guidance to federal and private companies on how remote working should be carried out. The Ministry makes clear that mothers with children between grades 1 and 9 should be prioritised for remote working, even when other employees return to work. Additionally, mothers of children in these grades are to be offered late starting times and early sign-off in order to support mothers should they choose to be with their children at the beginning and end of the school day. Such support is a first step towards supporting mothers so that they are not placed in a position to choose between motherhood and their employment.

Finally, early education centres, schools, and other social care centres should offer talking therapy to mothers, fathers, and their children (either in individual or group therapy) to support them as they transition back into less remote working, less online activities, and go back to some of the more familiar routines of their lives before March 2020. It would likewise be beneficial for schools to offer classes or spaces geared towards supporting the mental health of children as they also transition back into face-to-face learning. Although this project focused on parents, the children were always present and experienced their own challenges during ERL and should hence be supported.

Author Contributions: All authors worked on this manuscript in the following manner: The conceptualization of the paper was conceived by F.F.S.S., as was the writing of the methodology and formal analysis. The investigation and framing of the paper were conducted by F.F.S.S., N.J. and A.D., as was the writing of the original draft preparation. The writing, review, and editing were completed by F.F.S.S. N.J. and A.D. The project administration and funding acquisition were attained by F.S.F.S. All authors have read and agreed to the published version of the manuscript.

Funding: This research was funded by Zayed University, United Arab Emirates, as part of the emergency 2020 Short-Term Grant Programme (STG-011).

Institutional Review Board Statement: The study was conducted according to the guidelines of the Declaration of Helsinki and approved by the Ethics Committee of Zayed University (ZU20-102-F approved on 14th May 2020) and Research Review Board of the Ministry of Health and Prevention UAE (MOHAP/DXB-REC/ MJJ/No. 55/2020 approved on 6th June 2020).

Informed Consent Statement: Informed consent was obtained from all subjects involved in the study prior to data collection.

Acknowledgments: Emily Winchip, Rana Tamim, and Tabassim Ali at Zayed University, UAE, were also co-investigators on the project. The researchers would like to acknowledge the exemplary work undertaken by the two research assistants in the project, Maryam Jumaa Alawai (final year student at Zayed University majoring in Early childhood Education) in Abu Dhabi and Carla Baroudi in Beirut, Lebanon, who both tirelessly and diligently transcribed interviews and assisted in initial coding. Carla deserves special mention for her work despite the difficult situation she was living through in Beirut at the time.

Conflicts of Interest: The authors declare no conflict of interest. Likewise, the funders had no role in the design of the study; in the collection, analyses, or interpretation of data; in the writing of the manuscript, or in the decision to publish the results.

\section{Appendix A. Interview Questions}

1. If you were to reflect over the last few months, what would you say was the most challenging aspect of distance learning with your child(ren)?

2. As a parent what are you learning about learning process your children go through?

3. Did you learn something about your child(ren) you did not know?

4. What are you enjoying the most about your child(ren) learning at home?

5. What are you not enjoying about your child(ren) learning at home?

6. How are you managing your time between your work (if you are employed or other work) and ensuring that the child(ren) completed their work too?

7. What type of help are you/did you receive whilst your child(ren) were distance learning? (maids, extended families). 
8. How do you think your current living arrangements affect distance learning?

9. Do you have access to outside space?

10. If you were to describe this time of distance learning during the lockdown to your grandchildren, how would you describe it?

\section{Appendix B}

Table 1. Example of themes and their data sources.

\section{Challenges of Distance Learning}

- It's a good experience, but it takes a lot of time.

- We have five children at different grades, and some of them start their lessons at the same time, which makes it difficult to supervise them all at the same time.

- $\quad$ Online learning drains the child's and parent's energy due to the homework given by teachers every day, which leaves all the pressure on parents, especially if they have more than one child to take care of until the last hour of their day.

- It is time consuming. It is difficult to conduct when a parent has a fulltime job. It is not suitable for children in ECE (early childhood).

- $\quad$ Teachers should not rely on parents to fully educate the child and explain the materials alone.
Disproportionate Burden on Mothers

- I need to do this as a mother, it's my job to make sure they learn well, but even though I am not working, I am burned out and I am tired. But I have to do it, that's the way I see it.

- The mother cannot recover all homework because it's too much and she cannot reexplain all subjects. It's very difficult for all mother that cover everything due to many responsibilities that have.

- The combination of working and online learning with my kids has been difficult and extremely busy. It's effecting my mental health. As a mother I don't know ...

- The pressure of managing work with children's education was tough, mentally, emotionally and physically.

- I feel exhausted as a mother and instructor at $X$ institution. I feel that I am the primary teacher for my kids and now I am working more hours teaching in $\mathrm{X}$ institution and teaching my kids at home.

- During distance learning, as a working mother, we struggled on timings clashing.

\section{References}

Almeida, Marcela, Angela D. Shrestha, Danijela Stojanac, and Laura J.Miller. 2020. The impact of the COVID-19 pandemic on women's mental health. Archives of Women's Mental Health 23: 741-48. [CrossRef]

Andrew, Alison, Sarah Cattan, M. Costa Dias, Christine Farquharson, Lucy Kraftman, Sonya Krutikova, Angus Phimister, and Alumudena Sevilla. 2020. Parents, Especially Mothers, Paying Heavy Price for Lockdown. London: Institute for Fiscal Studies, Available online: https:/ /www.ifs.org.uk/publications/14861 (accessed on 23 January 2021).

Borah Hazarika, Obja, and Sarmistha Das. 2020. Paid and unpaid work during the Covid-19 pandemic: A study of the gendered division of domestic responsibilities during lockdown. Journal of Gender Studies. [CrossRef]

Braun, Virginia, and Victoria Clarke. 2013. Teaching thematic analysis: Overcoming challenges and developing strategies for effective learning. The Psychologist 26: 120-23.

Ceka, Ardita, and Rabije Murati. 2016. The role of parents in the education of children. Journal of Education and Practice 7: 61-64. Available online: https:/ / files.eric.ed.gov / fulltext/ EJ1092391.pdf (accessed on 23 November 2020).

Doody, Owen, and Maria Noonan. 2013. Preparing and conducting interviews to collect data. Nurse Researcher 20: 28-32. [CrossRef] [PubMed]

Erawati, Desi. 2020. Public perception of the mother's role in children's education (Sociological study of Kahayan Riverside Society In Palangka Raya City of Central Kalimantan). Journal of Research E Method in Education 6: 49-54. Available online: http:/ / www.iosrjournals.org/iosr-jrme/papers/Vol-6\%20Issue-6/Version2/F0606024954.pdf (accessed on 23 November 2020).

Fogle, Lyn W. 2013. Parental ethnotheories and family language policy in transnational adoptive families. Lang Policy 12: 83-102. [CrossRef]

Gallagher, Kay. 2019. Introduction: Education in the UAE-Context and Themes. In Education in the United Arab Emirates-Innovation and Transformation. Edited by Kay Gallagher. Singapore: Springer Nature, pp. 1-18.

Guy, Batsheva, and Brittany Arthur. 2020. Academic motherhood during COVID-19: Navigating our dual roles as educators and mothers. Gender, Work, and Organization 27: 887-99. [CrossRef] [PubMed]

Harkness, Sara, and Charles M. Super. 2006. Themes and variations: Parental ethnotheories in Western cultures. In Parenting Beliefs, Behaviors, and Parent-Child Relations: A Cross Cultural Perspective. Edited by Rubin Kenneth H. and Ock Boon Chung. New York: Psychology Press, pp. 61-80.

Harkness, Sara, Caroline Johnston Mavridis, Jia Ji Liu, and Charles M. Super. 2015. Parental ethnotheories and the development of family relationships in early and middle childhood. In Oxford Library of Psychology. The Oxford Handbook of Human Development and Culture: An Interdisciplinary Perspective. Edited by Lene A. Jensen. Oxford: Oxford University Press, pp. 271-91. [CrossRef] 
Johnston, Mary M., and Sara J. Finney. 2010. Measuring basic needs satisfaction: Evaluating previous research and conducting new psychometric evaluations of the Basic Needs Satisfaction in General Scale. Contemporary Educational Psychology 35: 280-96. [CrossRef]

Lee, Jaerim, Meejung Chin, and Miai Sung. 2020. How Has COVID-19 Changed Family Life and Well Being in Korea? Journal of Comparative Family Studies 51: 301-13. [CrossRef]

Manzo, Lidia Katia C., and Alessandra Minello. 2020. Mothers, childcare duties, and remote working under COVID-19 lockdown in Italy: Cultivating communities of care. Dialogues in Human Geography 10: 120-23. [CrossRef]

Matsa, David A., and Amalia R. Miller. 2014. Workforce reductions at women-owned businesses in the United States. Ilr Review 67: 422-52. [CrossRef]

McLaren, Helen Jaqueline, Karen Rosalind Wong, Kieu Nga Nguyen, and Komalee Nadeeka Damayanthi Mahamadachchi. 2020. Covid-19 and women's triple burden: Vignettes from Sri Lanka, Malaysia, Vietnam and Australia. Social Sciences 9: 1-11. [CrossRef]

Ministry of Human Resources and Emiritization (MoHRE). 2021. Available online: https://www.mohre.gov.ae/en/media-centre/ news /27/3/2020/regulating-remote-work-system-in-private-sector.aspx (accessed on 24 February 2021).

O'Neill, Rachel. 2016. The importance of a diverse and culturally competent workforce. Busidate 24: 9.

O'Reilly, Andrea. 2020. Trying to function in the unfunctionable: Mothers and COVID-19. Journal of the Motherhood Initiative 11: 7-24.

Pancsofar, Nadya, Jerry G. Petroff, Shridevi Rao, and Alyssa Mangel. 2019. "What I want to do as a father is be thee":Constructions of school involvement of fathers of children with complex disabilities. Research Practice for Persons with Severe Disabilities 44: 153-68. [CrossRef]

Russell, Beth Shoshana, Morica Hutchison, Rachel Tambling, Alexandria J. Tomkunas, and Abagail L. Horton. 2020. Initial challenges of caregiving during COVID-19: Caregiver burden, mental health, and the parent-child relationship. Child Psychiatry \& Human Development 51: 671-82.

Samuelson, Kristin W., Christina K. Wilson, Elena Padron, Suellen Lee, and Lauren Gavron. 2017. Maternal PTSD and children's adjustment: Parenting stress and emotional availability as proposed mediators. Journal of Clinical Psychology 73: 693-706. [CrossRef]

Self, Sharmistha, and Richard Grabowski. 2011. Is there gender bias in participation in early childhood education programs in developing countries? Role of mother's education. Journal of International Development 23: 909-25. [CrossRef]

Sher, Leo. 2020. The impact of the COVID-19 pandemic on suicide rates. QJM: An International Journal of Medicine 113: 707-12. [CrossRef] [PubMed]

Smith, Joanna, and Jill Firth. 2011. Qualitative data analysis: the framework approach. Nurse Researcher 18: 52-62. [CrossRef] [PubMed]

Stebbins, Robert A. 2001. Exploratory Research in the Social Sciences. London: Sage, vol. 48.

Taneja, Sonia, Mildred Golden Pryor, and Jennifer Oyler. 2012. Empowerment and gender equality: The retention and promotion of women in the workforce. Journal of Business Diversity 12: 43-53.

UNESCO. 2020a. Education in a Post-COVID World: Nine Ideas for Public Action. Available online: https://unesdoc.unesco.org/ark: /48223/pf0000373717 (accessed on 23 November 2020).

UNESCO. 2020b. UNESCO COVID-19 Education Response: How Many Students Are at Risk of not Returning to School? Available online: https:// unesdoc.unesco.org/ark:/48223/pf0000373992?locale=en (accessed on 23 November 2020).

UNESCO. 2020c. UNESCO COVID-19 Education Response-Education Sector Issue Notes No. 2.3. April. Available online: https: / / unesdoc.unesco.org/ark:/48223/pf0000373512 (accessed on 23 November 2020). 